\title{
COMPLEX GEOPHYSICAL SOLUTION FOR SEISMOHYDROGEOLOGICAL PROBLEMS OF BALNEOLOGY IN MONGOLIA
}

\author{
S.P. Serebrennikov ${ }^{1}$, V.I. Dzhurik ${ }^{1}$, Ts. Batsaikhan ${ }^{2}$, A.F. Drennov ${ }^{1}$. \\ 'Institute of the Earth's Crust SB RAS, Irkutsk, Russia \\ ${ }^{2}$ Research Center of Astronomy and Geophysics MAS, Ulaanbaatar, Mongolia \\ batsaihan@rcag.ac.mn
}

\begin{abstract}
The present paper is concerned with geophysical trends of particular importance to organizing, planning and building resorts in Mongolia. The possibilities for integrated geophysical and engineering-seismological investigations have been demonstrated with the resort construction site near Ulaanbaatar town. The investigations have resulted in obtaining thickness of loose deposits, depth of groundwater occurrence, and estimates of relative seismic hazard and soil conditions. Two aquifers have been presumably identified and parameters of seismic effects have been estimated for expectable earthquakes as applied to two potential levels of initial seismic activity in Ulaanbaatar town. This provides an example of the possibility of finding complex solution to seismohydrogeological problems of balneology in seismically active areas throughout Mongolia.
\end{abstract}

\section{Physical basis of geophysical methods employed in balneology}

The use of instrumental methods in scientific research in the field of balneology covering the occurrence of mineral water springs is associated with the interaction of geophysical and physical parameters of soils and mineral waters. In the former, these are elastic and electric parameters: density, moisture, temperature, and others. In the latter case, these are the parameters of filtration field, mineralization, and occurrence and movement of groundwater (Serebrennikov et al., 2006). Moreover, the resorts should be designed, constructed and maintained with due regard for hydrogeological environment of the development area that determines site selection, planning, and a probability of predicting the ecological consequences of environmental disturbance and much of local seismic events in seismically active areas. From the above reasoning, this paper discusses the potentialities of geophysical methods in the identification of aquifers, determination of soil texture and conditions, and soil seismic hazard assessment. These are three basic trends in exploration geophysics, particularly important to organizing, planning and building resorts in Mongolia, which might also involve the use of shallow-to-moderate-depth ground investigation (Soil conditions..., 1988; Seismic zoning..., 1971).

The above-mentioned geophysical investigations have been carried out in both Mongolia and Russia. The investigative techniques and tasks have been associated with the 
problems of resort planning and competitive selection of sites. The investigations have been performed using up-to-date digital seismic and electric instruments.

The vertical electric sounding (VES) suggests the possibility of providing vertical geological section, study of spatial location of geobodies having different electric properties, and determination of thickness for low-resistance "water-saturated" layers and depth of occurrence for reference horizons. In this case, the field measurements can be interpreted both qualitatively and quantitatively from one-dimensional analysis of each VES curve followed by subsurface geologic imaging and mapping. Both this and hydrogeological interpretations are associated with widely used computer technology and software products (Geoelectric survey..., 1986).

Seismic measurements have been made to provide characteristics for seismicity of soils in addition to those from engineering geology and hydrogeology. Direct measurements and refraction observations have been performed by the standard technique using a system of reversed and catching-up time-distance curves (Seismic survey..., 1981). The main advantage of the technique in hydrogeology is that it determines the velocity ratio of longitudinal and transverse wave velocities and Young's modulus in air-dry, loose watersaturated and solid soils. Note that these parameters have received little use because of low determination accuracy. The complex approach employed herein has improved the accuracy and reliability of measurements.

\section{Investigation results}

The heath resort site is situated in the intermountain valley on the left bank of the Tola River, in proximity to the existing airport. The site area is about one $\mathrm{km}^{2}$ (Fig. 1).

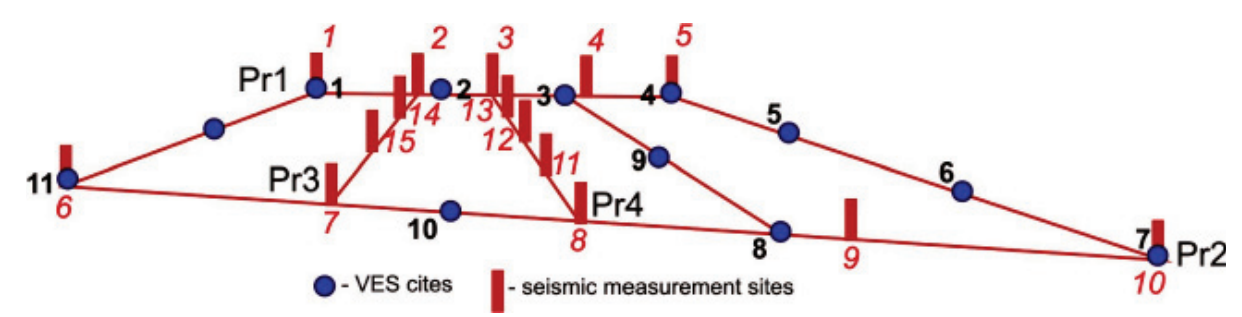

Fig. 1. Geophysical profiles, VES sites (circles) and seismic measurement sites (columns) located on the construction area.

The fieldwork instruments and procedures have involved seismic measuring by the refracted wave method using 24-channel digital station "Diogen-2005" (Russia). The station can operate in desired signal accumulation or subtraction mode. Individual measurements have been made using the reversed and catching-up time-distance curves performed at the beginning of the survey (Seismic survey..., 1981). The time-distance curves have been $79 \mathrm{~m}$ long; seismic motions have been produced by using blows (Dzhurik et al., 2008b). 
Geoelectrics has been performed by the vertical electric sounding (VES) with digital device "Electrotest-C" (Russia). This device has a self-contained AB power supply and can operate at a constant and alternating current. Three accumulation modes permit the electric noise performance and the storage of measurement results in a volatile device memory. Individual measurements have been performed with an accuracy of 4-8\%, provided by the remeasuring procedure (Dzhurik et al., 2008a).

The seismic and geoelectric measurements have been interpreted using special programs designed at the Moscow State University (Russia). A total of 12 VES surveys has been uniformly performed throughout the investigated site with the $A B / 2$ spacing of 200 $\mathrm{m}$. The same area has been covered by 14 seismic surveys (see Fig. 1).

The measuring sites have been located relative to the employer-provided area survey stakes using GPS geodesy and the photo clearly showing geomorphological features of the survey area (Fig. 1). In the photo, we emphasize nearly absolute precision. The measuring sites have been also staked out.

A dense grid of measurement data produced velocity and apparent and true resistivity sections that are basic to solving the foregoing problems.

The seismic survey resulted in four seismogeological sections along profiles 1-4 (Fig. 4). The first profile along the left side of the intermountain valley has been obtained by shots $1-5$. The first (I) layer with thickness $2-3 \mathrm{~m}$ and velocities $300-460 \mathrm{~m} / \mathrm{s}$ is rather persistently disposed along the length of the profile.

The second (II) layer consists of loose to dense deposits with the velocity being nearly twice as high as that for the first layer and varying from 620 to $760 \mathrm{~m} / \mathrm{s}$ for longitudinal (Vp) waves and from 280 to $340 \mathrm{~m} / \mathrm{s}$ for transverse (Vs) waves to a depth of $12-14 \mathrm{~m}$. The velocities of seismic waves increase further along the section whose deposits change to coarse materials (IV) with velocities of $1050-1250 \mathrm{~m} / \mathrm{s}$ for Vp and $530-630 \mathrm{~m} / \mathrm{s}$ for Vs. At a depth of 14-16 m, this layer is underlain by the water-saturated soils (III) with velocities of $1520-2100 \mathrm{~m} / \mathrm{s}$ for $\mathrm{Vp}$ and $620-1700 \mathrm{~m} / \mathrm{s}$ for Vs.

An easier section of profile 2 along the right side of the valley consists of two velocity layers (Fig. 2). The upper layer (IV) 8-10 thick is attributed to coarse-grained, decomposed and fractured soils whose velocities along the profile are rather persistent: $1100-1200 \mathrm{~m} / \mathrm{s}$ for Vp and $540-600 \mathrm{~m} / \mathrm{s}$ for Vs. 

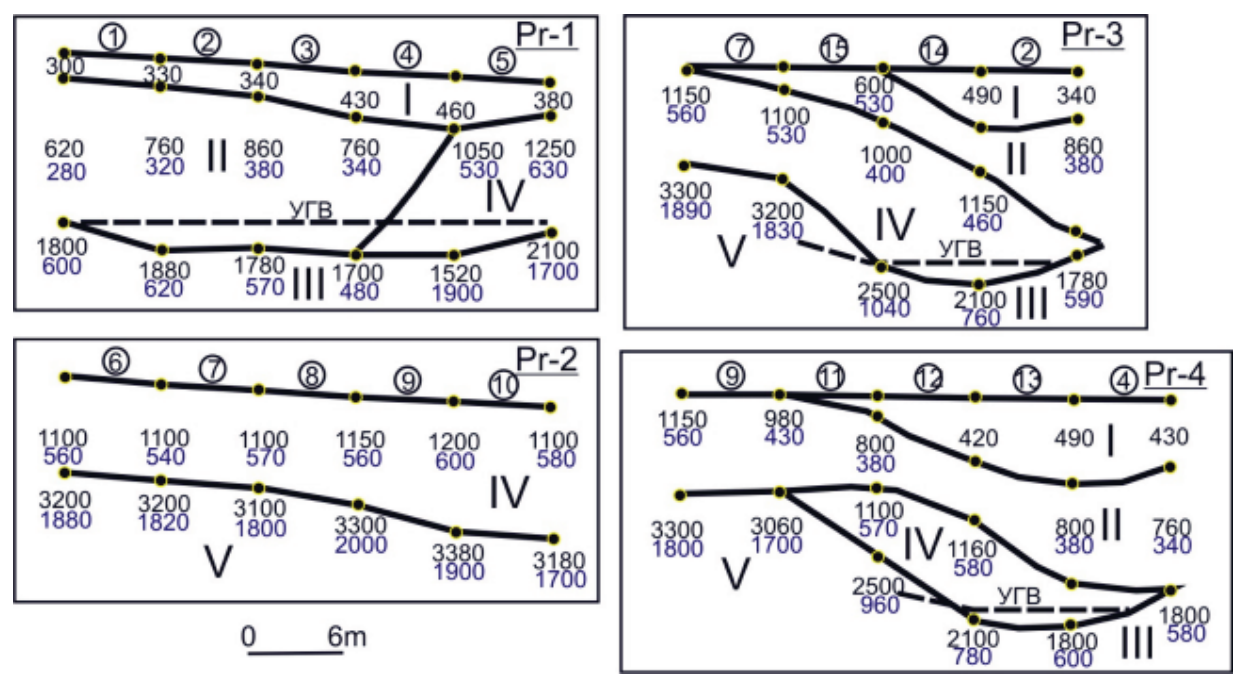

Fig. 2. Geological-geophysical sections along profiles 1-4 (see Fig. 1). The figures show the velocities of longitudinal (top) and transverse (bottom) waves in the layers identified (I-V).

Profile 3 across sites 7, 15, 14 and 2 (Fig. 2) and Profile 4 across sites 8, 11, 12, 13 and 3 (Fig. 2) are more complex structures though the layers identified in the profiles have been almost classified by the foregoing velocity of seismic waves. The weak zone at sites 11 and 15 raises the question as to whether the soil weakness is due to the presence of fault or higher fracturing of solid soils, whereas wave velocity profiles determined from wave measurements at sites 13 and 14 have shown the lowest points in equivalent rock topography.

The VES sounding in the site area have been conducted to identify aquifers and the depth of occurrence of solid soils. A technique for improving the data reliability has been associated with the performance of electric soundings in the immediate vicinity of the two nearest hydrogeological boreholes for which the depth of groundwater occurrence and geological structure are known. The first borehole is located to the southwest (upstream) of the site and the second is to the north (downstream) of it near the airport road. The penetrated aquifer horizons $\mathrm{H}$ are shown by the curves associated with QQHKH and QHKH types (Geoelectric survey..., 1986). The electrical resistances of the aquifers attain their minimum values of 34 and $77 \mathrm{Ohmm}$ at respective depths of $8-15 \mathrm{~m}$ in the first case (Borehole 1, Fig. 3) and 17-47 $\mathrm{m}$ in the second (Borehole 2, Fig.3). These boreholes have been used as a parametric basis for interpreting the VES curves obtained from the resort construction site.

Three- and four-layer VES curves of AA, KHA, KH, QHA, HA and other types have been recorded on the site area in addition to the above-mentioned. The curves reliably trace the boundaries of aquifers varying in resistance from 40 to $65000 \mathrm{Ohmm}$. Table 1 lists the VES curve interpretations of two profiles across the center of the site. 

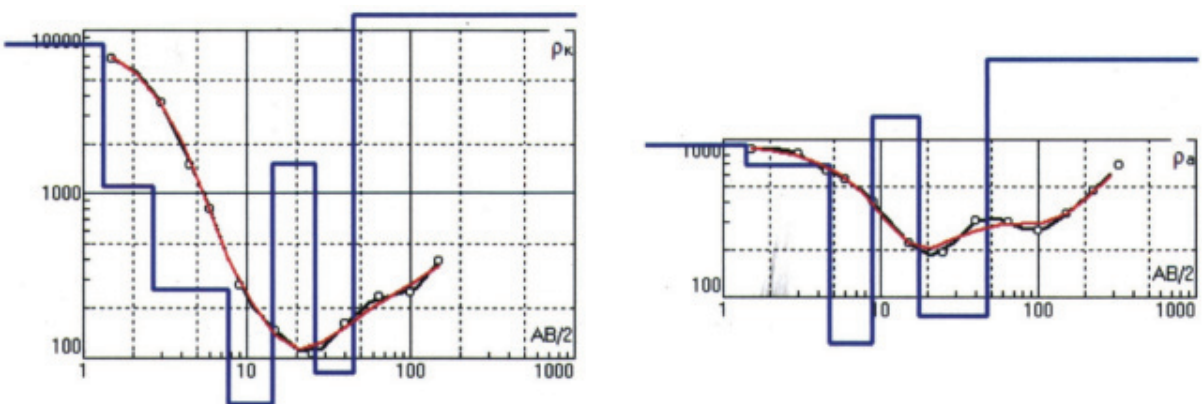

\begin{tabular}{|c|c|c|c|c|}
\hline $\mathrm{N}$ & $\mathrm{p}$ & $\mathrm{h}$ & $\mathrm{d}$ & Alt \\
\hline 1 & 8173 & 1,32 & 1,32 & $-1,323$ \\
\hline 2 & 1101 & 1,34 & 2,66 & $-2,659$ \\
\hline 3 & 259 & 5,1 & 7,76 & $-7,76$ \\
\hline 4 & 34,6 & 6,51 & 14,3 & $-14,27$ \\
\hline 5 & 1520 & 11,7 & 25,9 & $-25,93$ \\
\hline 6 & 81,9 & 18,8 & 44,7 & $-44,7$ \\
\hline 7 & 24134 & & & \\
\hline
\end{tabular}

\begin{tabular}{|c|c|c|c|c|}
\hline $\mathrm{N}$ & $\mathrm{p}$ & $\mathrm{h}$ & $\mathrm{d}$ & Alt \\
\hline 1 & 917 & 1,39 & 1,39 & $-1,39$ \\
\hline 2 & 688 & 3,33 & 4,72 & $-4,72$ \\
\hline 3 & 51,6 & 4,12 & 8,84 & $-8,84$ \\
\hline 4 & 1407 & 8,59 & 17,4 & $-17,43$ \\
\hline 5 & 76,9 & 29,6 & 47 & $-47,03$ \\
\hline 6 & 7758 & 59,2 & 106 & $-106,2$ \\
\hline 7 & 37331 & & & \\
\hline
\end{tabular}

Fig. 3. VES curves recorded on the hydrogeological borehole sites and their quantitative interpretation.

Table 1

Quantitative interpretations of VES curves

\begin{tabular}{|c|c|c|c|c|c|c|c|}
\hline \multicolumn{2}{|c|}{ VES No. 1} & \multicolumn{2}{|c|}{ VES No. 2} & \multicolumn{2}{|c|}{ VES No. 3} & \multicolumn{2}{|c|}{ VES No. 4} \\
\hline $\begin{array}{c}\rho \\
(\mathrm{Ohmm})\end{array}$ & $\begin{array}{c}\mathrm{h} \\
(\mathrm{m})\end{array}$ & $\begin{array}{c}\rho \\
(\mathrm{Ohmm})\end{array}$ & $\begin{array}{c}\mathrm{h} \\
(\mathrm{m})\end{array}$ & $\begin{array}{c}\rho \\
(\mathrm{Ohmm})\end{array}$ & $\begin{array}{c}\mathrm{h} \\
(\mathrm{m})\end{array}$ & $\begin{array}{c}\rho \\
(\mathrm{Ohmm})\end{array}$ & $\begin{array}{c}\mathrm{h} \\
(\mathrm{m})\end{array}$ \\
\hline 66 & 4,6 & 164 & 4 & 71 & 3,5 & 117 & 3 \\
\hline 214 & 19 & 264 & 18 & 201 & 21 & 146 & 20 \\
\hline 475 & 54 & 536 & 55 & 469 & 56 & 869 & 48 \\
\hline 62000 & & 36000 & & 28000 & & 33000 & \\
\hline \multicolumn{2}{|c|}{ VES NO.5 } & \multicolumn{2}{|c|}{ VES NO.6 } & \multicolumn{2}{|c|}{ VES NO.7 } & \multicolumn{2}{|c|}{ VES NO.8 } \\
\hline $\begin{array}{c}\rho \\
(\mathrm{Ohmm})\end{array}$ & $\begin{array}{c}\mathrm{h} \\
(\mathrm{m})\end{array}$ & $\begin{array}{c}\rho \\
(\mathrm{Ohmm})\end{array}$ & $\begin{array}{c}\mathrm{h} \\
(\mathrm{m})\end{array}$ & $\begin{array}{c}\rho \\
(\mathrm{Ohmm})\end{array}$ & $\begin{array}{c}\mathrm{h} \\
(\mathrm{m})\end{array}$ & $\begin{array}{c}\rho \\
(\mathrm{Ohmm})\end{array}$ & $\begin{array}{c}\mathrm{h} \\
(\mathrm{m})\end{array}$ \\
\hline 107 & 2,5 & 723 & 3,5 & 741 & 3 & 234 & 3,5 \\
\hline 455 & 2 & 65 & 6 & 155 & 4,6 & 1670 & 22 \\
\hline 213 & 10 & 1900 & 21 & 5300 & 17 & 1370 & 33 \\
\hline 92 & 15 & 139 & 10 & 10000 & & 15500 & \\
\hline 35000 & & 23000 & & & & & \\
\hline
\end{tabular}

Most of the curves have three or four layers (see Table 1). The upper layer of seasonally frozen soil with thickness $2-3 \mathrm{~m}$ has an electric resistance ranging from 66 to 723 Ohmm. The second layer with average thickness $20 \mathrm{~m}$ has an electric resistance approximating $200 \mathrm{Ohmm}$. The second layer increases in thickness towards the site center, and then it exhibits thickness decrease towards the sides of the valley, largely associated with decomposed and fractured soils. The weakest zone attains thickness of between $50-70 \mathrm{~m}$ in the third sounding site (VES No. 3) (Table 1). 
Integrated interpretation of geological-geophysical data may provide a model of the investigated site. The velocities of seismic waves and electrical resistivities of soils can be used as a basic guideline in distinguishing the layers by structure and conditions that is based upon the following premises. As the velocity of seismic waves in water-saturated and air-dry soils increases, so do the strength and volume of the soils. However, the velocities of longitudinal waves in similar soils are much higher than in dissimilar, and the velocities of transverse waves in similar and dissimilar soils are comparable to each other. This also enabled us to identify the layers by velocity ratio of longitudinal and transverse waves and, therefore, to infer the level depth of occurrence for water-saturated soils or groundwater in addition to the lithological boundary.

The electrical resistivities of soils tend to decrease with increase in soil moisture and mineralization. The resistivity decrease has been reliably shown within each electrical profile using the interpretation of VES curves.

The locating model closely corresponds to the data on geophysical sections along profiles 1 and 2 (Fig. 2). This model should only be only interpreted in terms of seismohydrogeology that provides the following basic parameters. Loose and macrofragmental water-unsaturated soils predominantly extend to a depth of $14 \mathrm{~m}$ below the surface, highmoisture content soils occur at the depth between 14 and $24 \mathrm{~m}$ below, and solid soils with fracturing and low filtration properties lie at a depth between 24 and $30 \mathrm{~m}$ below the surface. The low-resistance solid soils extending downward from $30 \mathrm{~m}$ below are taken to be water-saturated.

These results may be important for estimating the variation of seismic hazard at the site in relation to soil conditions and structure. The initial sesimicity is currently being refined for the area of Ulaanbaatar town though the construction involves the approved map of 1985 (Earthquakes..., 1985; БНбД 22.01*/2006) whereon Ulaanbaatar is assigned to the zone of intensity 7. Considering probable increase in initial seismicity that is due in particular to building criticality rating (SNiP II-7-81*; БНбД 22.01*/2006), we show the initial seismic hazard results (in intensity units) obtained for two levels and the design acceleration values for the second (intensity of 8) level. This enables the builders to foresee all probable variants for competitive selection of sites. 

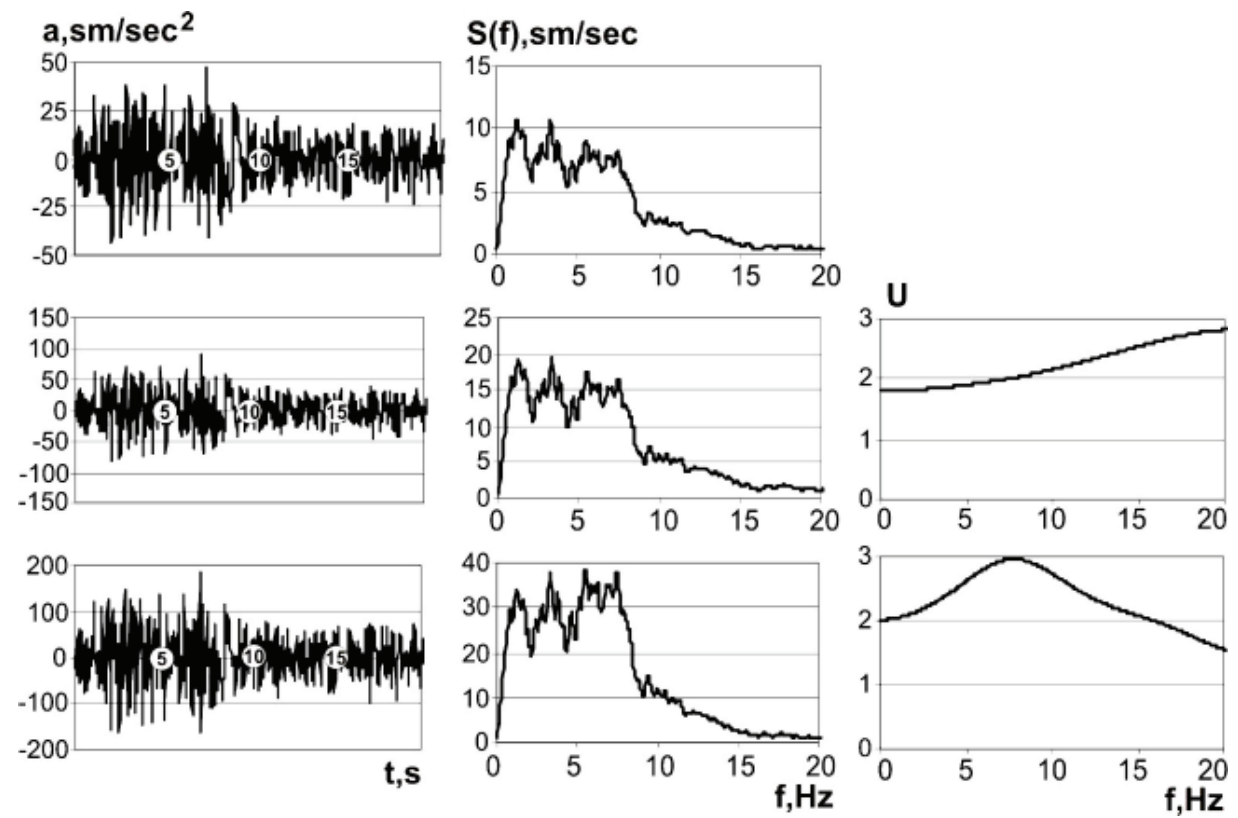

Fig. 4. Initial and design accelerograms (a), their spectra (b) and frequency characteristics (c) for models 1 and 2 (maximum horizontal component).

Accelerograms and their spectra and characteristics have been computed using the technique presented in (Dzhurik, et al., 2008; Dzhurik et al., 2005) with the initial signal scaled for hard soils, and yet with regard to initial seismic intensity of 8 (Fig. 4). The basic parameters of the initial signal are as follows: motion duration $20 \mathrm{~s}$ at 0.7 maximum, peak acceleration $46.9 \mathrm{~cm} / \mathrm{s}^{2}$, and the spectrum attaining the maximum $(10.4 \mathrm{~cm} / \mathrm{s})$ at a frequency approximating $1 \mathrm{~Hz}$.

In Table 2 are given the parameters for two models sufficient to perform calculations with regard to homogeneous seismic properties of the site.

Table 2

Parameters of generalized seismic models for health resort site

\begin{tabular}{|c|c|c|c|c|}
\hline Model No. & $\mathrm{h}(\mathrm{m})$ & $\mathrm{Vp}(\mathrm{m} / \mathrm{s})$ & $\mathrm{Vs}(\mathrm{m} / \mathrm{s})$ & $\rho\left(\mathrm{t} / \mathrm{m}^{3}\right)$ \\
\hline 1 & 2 & 3 & 4 & 5 \\
\hline \multirow{3}{*}{1} & 8 & 1100 & 540 & 2.2 \\
& $\infty$ & 3000 & 1700 & 2.6 \\
\hline \multirow{4}{*}{2} & 3 & 400 & 200 & 1.8 \\
& 11 & 800 & 380 & 2.0 \\
& 10 & 2400 & 1300 & 2.5 \\
& $\infty$ & 3000 & 1700 & 2.6 \\
\hline
\end{tabular}


For the calculations involved in this approach, the angle of incidence of the initial signal upon the simulated layer pattern (Table 2) has been close to $30^{\circ}$. This is the most probable angle of radiation for most of the earthquakes recorded by seismic stations in Ulaanbaatar. With the effect of selected parameters on bottom site, the ground accelerations will be 89 and $186 \mathrm{~cm} / \mathrm{s}^{2}$ (Fig. 4a). In this case, the maximums of the spectra will be 19.6 and $38 \mathrm{~cm} / \mathrm{s}$ (Fig. 4b). The frequency characteristics are inherent in the loose upper layers overlying the bedrock and do not depend on the levels of effect. Because of this, the resonance frequency for the two foregoing initial seismicity levels will be 20 and $8.2 \mathrm{~Hz}$.

A relative change in seismic shaking hazard measured in seismic intensity units can be calculated from the velocities of seismic waves in reference to benchmark soils (Medvedev, 1962). Seismic intensity increment is quantitatively determined with logarithmic relationship (Complex..., 2004) showing that a 4-fold change in seismic rigidity (pV) of the upper soils in reference to the selected benchmark corresponds to a 1-unit intensity change in seismic hazard.

The possible velocities in the benchmark and average soils selected from the earlier (Dzhurik et al., 2008a) and current measurement estimates have been respectively 2400 $\mathrm{m} / \mathrm{s}$ and close to $600 \mathrm{~m} / \mathrm{s}$, and the respective volumes of these soils are $2.5 \mathrm{t} / \mathrm{m}^{3}$ and $1.9 \mathrm{t} /$ $\mathrm{m}^{3}$.

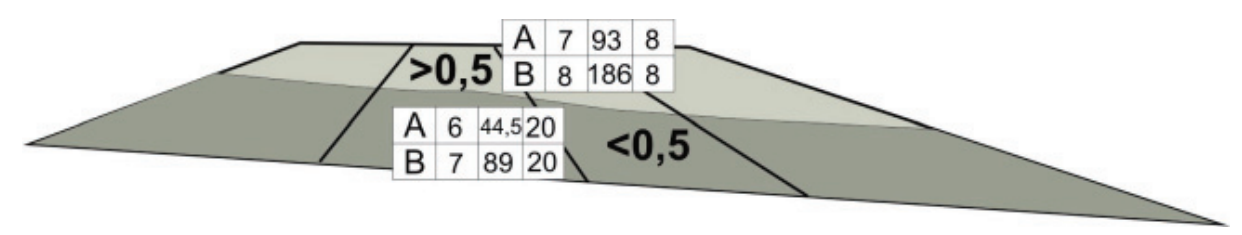

Fig. 5. Seismic hazard zoning of the recreation site. A - initial seismic intensity 7, B - initial seismic intensity 8.

Figures from top to bottom are seismic hazard design values (intensity units); peak accelerations $\left(\mathrm{cm} / \mathrm{s}^{2}\right)$; resonance frequency of loose ground layer $(\mathrm{Hz})$.

Seismic hazard calculation using intensity units allowed dividing the investigated area into two parts, with the intensity increments 0.5 units lower and 0.5 units higher in reference to benchmark soils (Fig. 5). In this case, the site is distributed into the areas exposed to seismic intensity 6 or 7 (intensity increment $<0.5$ ) and 7 or 8 (intensity increment $>0.5$ ) in accordance to two initial seismicity levels.

Note that the site is favorable for construction because of the fact that groundwater occurs at a depth lower than $10 \mathrm{~m}$ and seismic wave velocities in shallow soil deposits are rather high (layer V, Fig. 2). This is also typical of loose (layer II) and coarse (layer IV) deposits. In this connection, the designed acceleration values are somewhat lower than the average accelerations in an intensity scale even for initial seismicity of 8 .

The theoretical calculations have been performed assuming elastic deformations or release of energy that may appear in elastic motions. The permanent elastic deformations can be determined from the designed acceleration values in seismic scales. In any event they are approximate solutions as the change in characteristics of soils in going from elas- 
tic to non-elastic motions is approximate and not understood.

\section{Conclusions}

The site $\left(1 \mathrm{~km}^{2}\right)$, which is intended for resort construction in the intermountain basin in the southern part of the Tola River valley (in proximity to the airport) has been covered by geophysical survey measured the distribution of seismic wave velocities and electrical resistances in addition to theoretical calculations. This work, combined with the geological interpretation, has resulted in obtaining loose sediment thickness, groundwater occurrence depth, and estimates of relative seismic hazard and soil conditions. Two aquifers have been presumably identified and variations of seismic hazard have been estimated at seismic intensity units and ground accelerations over the site in case of potentially large earthquakes with regard to two potential levels of initial seismicity in Ulaanbaatar town. This provides an example of finding complex solution to the foregoing problems associated with seismohydrogeology and construction.

The herein methods for probability-based design may be of utility to the area of Ulaanbaatar town. The map for earthquake statistics (Earthquakes..., 1985) shows that earthquakes of intensity 7 occurred once every 1000 years prior to the Deren earthquake (Complex..., 2004) although the estimation procedure adopted to the Russian conditions assumes the later events at issue could have occurred once every 500 years at a $200-\mathrm{km}$ radial distance from Ulaanbaatar. To a first approximation, it corresponds to $10 \%$ probability of exceedance of design earthquakes (initial intensity 7) in 50 years (SNiP II-7-81*). Considering that the probability-based estimates have been made on individual cases, the presently accepted recurrence intervals might be reasonable for individual earthquakes of intensity 8 occurring once every 1000 years. This is conveniently illustrated by the recurrence curve for the Tola area with regard to the Mogod earthquakes (Earthquakes..., 1985).

Therefore, the second variant estimate might be reasonable for shaking intensity 8 with $5 \%$ probability of exceedance in 50 years $(\mathrm{T}=100$ years). A proper estimate will be associated with development of aseismic measures in constructing facilities with high criticality rating on the selected site.

This research has been done under support RFBR (project 08-0590204-Monq_a).

\section{References}

БНбД 22.01*/2006.Газар ходлолтийн бус нутагт барилга толовлох барилгийн норм ба дурэм. Монгол улсын Барилга, хот байгуулалтын яам. Улаанбаатар хот 2006 он. 42 стр.

Complex geophysical and seismological investigation in Mongolia. (2004). - Dzhurik, V.I. \& Dugarmaa, T. (eds.). - MAS, Ulaanbaatar, 315 pp.

Dzhurik, V.I., Dugarmaa, T., Serebrennikov, S.P. \& Batsaikhan, Ts. (2008). - Seismic hazard assessment for the site areas in the neighborhoods of Ulaanbaatar town based on seismotectonic data (using the airport runway as an example). - Proceedings of MAS, 4, 182, 17-30.

Dzhurik, V.I., Batsaikhan, Ts., Serebrennikov, S.P. \& Usynin, L.A. (2008a). - Comprehensive as- 
sessment of seismic hazard for building construction sites in Ulaanbaatar town. - Proceedings of MAS, 4, 182, 17-30.

Dzhurik, V.I., Batsaikhan, Ts., Drennov, A.F., Serebrennikov, S.P. \& Dugarmaa, T. 2005). - Initial accelerograms of strong-motion earthquakes for hard soil in Ulaanbaatar. - Proceeding of the V Russian-Mongolian Conference on Astronomy and Geophysics. - Irkutsk, 12-15 (in Russian).

Dzhurik, V.I., Serebrennikov, S.P., Eskin, A.Yu. \& Usynin, L.A. (2008b). - Probabilistic seismic hazard assessment for the urban areas of the Mongolo-Siberian region. - Vestnik IrGTU, 4, 18-25 (in Russian).

Earthquakes and guidelines for seismic zoning of Mongolia. (1985) - Nauka, Moscow, 230 pp. (in Russian).

Geoelectric survey. Geophysicists Guidebook. (1986). - Nedra, Moscow, 440 pp. (in Russian).

Medvedev, S.V. (1962). - Engineering seismology. - Gosstroiizdat, Moscow, 260 pp. (in Russian).

Seismic zoning of Ulaanbaatar. (1971) - Nauka, Moscow, 202 pp. (in Russian).

Seismic survey. Geophysicists Guidebook. (1981). - Nedra, Moscow, 460 pp. (in Russian).

Serebrennikov, S.P., Dzhurik, V.I. \& Batsaikhan, Ts. (2006). - Shallow-depth geophysical solution for seismohydrogeological and engineering-geological problems of balneology in Mongolia. - Proceedings of the VI Russian-Mongolian Conference on Astronomy and Geophysics. Irkutsk, 39-43 (in Russian).

SNiP II-7-81*. Earthquake engineering / Gosstroi Rossii. (2001). - GUP TSPP, Moscow, 44 pp. (in Russian).

Soil conditions in seismic hazard assessment. (1988). - Seismic microzoning guidance. - Nauka, Moscow, 280 pp. (in Russian). 